\title{
Hybrid coronary revascularization: Midterm outcomes of robotic multivessel bypass and percutaneous interventions
}

\author{
Hiroto Kitahara, MD, ${ }^{\mathrm{a}}$ Taishi Hirai, MD, ${ }^{\mathrm{b}}$ Mackenzie McCrorey, PA, ${ }^{\mathrm{a}}$ Brooke Patel, MSN, \\ Sarah Nisivaco, BS, ${ }^{a}$ Sandeep Nathan, MD, ${ }^{b}$ and Husam H. Balkhy, MD $^{a}$
}

\section{ABSTRACT}

Objective: The purpose of this study was to investigate the outcomes of patients undergoing advanced hybrid coronary revascularization, defined as robotic beating-heart multivessel totally endoscopic coronary artery bypass combined with percutaneous coronary intervention.

Methods: This is a retrospective study. Among 308 consecutive patients who underwent totally endoscopic coronary artery bypass, 57 who underwent advanced hybrid coronary revascularization (mean age, 65.6 years) from July 2013 to September 2017 were included. Midterm survival and freedom from major adverse cardiac events, including death, myocardial infarction, and repeat revascularization, were analyzed.

Results: Multivessel totally endoscopic coronary artery bypass was successfully performed without conversion to thoracotomy. Bilateral internal thoracic artery grafting was used in 50 patients $(87.7 \%)$. The mean operative time was $318.4 \pm 51.0$ minutes. The mean length of hospital stay was $3.0 \pm 1.3$ days. There was no 30-day mortality. Percutaneous coronary intervention was planned after totally endoscopic coronary artery bypass in 51 patients $(89.4 \%)$. The target lesions were the right coronary artery only in 38 patients, the left circumflex artery only in 4 patients, and multiple lesions in 13 patients. Eventually, 2 patients did not receive percutaneous coronary intervention. Percutaneous coronary intervention attempt was unsuccessful in 8 lesions. Patency of the left/right internal thoracic artery was $95.2 \%(60 / 63)$ and $95.7 \%$ (45/47), respectively. Graft patency was $95.2 \%$ (40/42) in the left circumflex artery and 93.3\% (14/15) in the diagonal branch. Three-year survival was $92.8 \%$, and 3-year freedom from major adverse cardiac events was $80.2 \%$.

Conclusions: Advanced hybrid coronary revascularization is a safe and lessinvasive approach with short hospital stay and good midterm outcomes. (J Thorac Cardiovasc Surg 2019;157:1829-36)

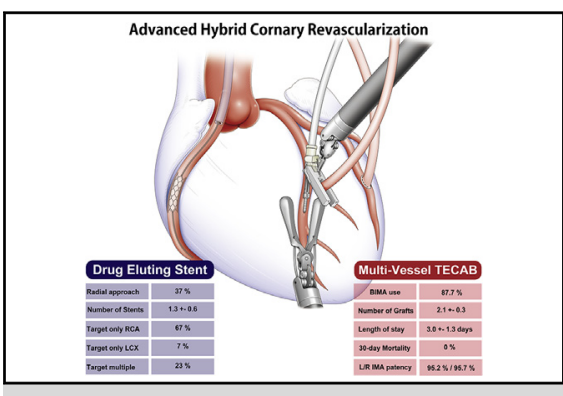

Beating-heart multivessel endoscopic coronary bypass and percutaneous intervention.

\section{Central Message}

The outcomes of multivessel totally endoscopic bypass with percutaneous intervention at our center were acceptable with short hospital stay, low morbidity rate, and survival at midterm follow-up.

\section{Perspective}

AHCR (robotic beating-heart multivessel TE$\mathrm{CAB}$ combined with $\mathrm{PCI}$ ) can be a viable option for selected patients seeking early functional recovery after surgery for multivessel coronary artery disease.

See Commentaries on pages 1837 and 1839.
Hybrid coronary revascularization has emerged as a lessinvasive approach for multivessel coronary artery disease along with the development of minimally invasive cardiac

From the ${ }^{\text {a Section }}$ of Cardiac and Thoracic Surgery, Department of Surgery and ${ }^{\mathrm{b}} \mathrm{Sec}-$ tion of Cardiology, Department of Medicine, The University of Chicago Medicine, Chicago, Ill.

Read at the 98th Annual Meeting of The American Association for Thoracic Surgery, San Diego, California, April 28-May 1, 2018.

Received for publication Jan 16, 2018; revisions received July 29, 2018; accepted for publication Aug 13, 2018; available ahead of print Jan 8, 2019.

Address for reprints: Husam H. Balkhy, MD, Section of Cardiac and Thoracic Surgery, Department of Surgery, The University of Chicago, 5841 S Maryland Ave, MC5040, Chicago, IL 60637 (E-mail: hbalkhy@ surgery.bsd.uchicago.edu). $0022-5223 / \$ 36.00$

Copyright (c) 2018 by The American Association for Thoracic Surgery https://doi.org/10.1016/j.jtcvs.2018.08.126 surgery. The main advantage of hybrid revascularization is to realize the surgical benefits of the internal thoracic artery graft to the left anterior descending (LAD) artery and to achieve complete revascularization with percutaneous coronary intervention (PCI) to the non-LAD vessels, the latter of which has been shown to have similar or perhaps even

Uf Scanning this QR code will
take you to the article title
page to access supplementary
information. To view the
AATS Annual Meeting Web-
cast, see the URL next to the
webcast thumbnail.




$$
\begin{aligned}
& \text { Abbreviation and Acronyms } \\
& \text { AHCR }=\text { advanced hybrid coronary } \\
& \text { revascularization } \\
& \text { BITA } \text { bilateral internal thoracic artery } \\
& \text { CABG }= \text { coronary artery bypass grafting } \\
& \text { LAD }=\text { left anterior descending } \\
& \text { LCX }=\text { left circumflex artery } \\
& \text { LITA }=\text { left internal thoracic artery } \\
& \text { MACE }= \text { major adverse cardiac events } \\
& \text { MIDCAB }= \text { minimally invasive direct coronary } \\
& \text { artery bypass } \\
& \text { PCI }= \text { percutaneous coronary intervention } \\
& \text { RCA }= \text { right coronary artery } \\
& \text { RITA }= \text { right internal thoracic artery } \\
& \text { TECAB }= \text { totally endoscopic coronary artery } \\
& \text { bypass }
\end{aligned}
$$

better long-term patency compared with saphenous vein grafts in non-LAD target vessels. ${ }^{1}$ Minimally invasive direct coronary artery bypass (MIDCAB) has been used in hybrid revascularization approaches and with acceptable outcomes. ${ }^{2}$ This procedure has been shown to be noninferior to conventional coronary artery bypass grafting (CABG) ${ }^{3}$ Totally endoscopic coronary artery bypass (TE$\mathrm{CAB}$ ) has been reported as an alternative approach as a least-invasive surgical coronary revascularization technique. ${ }^{4,5}$ In addition to its less-invasive nature, the advantage of TECAB is the capability of applying multivessel surgical revascularization using bilateral internal thoracic artery (BITA) grafts to bypass not only the LAD but also branches of the left circumflex artery (LCX) using a totally endoscopic approach. ${ }^{6}$ The survival benefit of BITA graft use in CABG has been well documented (especially in diabetic patients) ${ }^{7}$; thus, theoretically, multivessel TECAB with BITA grafts would also be more favorable as a surgical arm of hybrid coronary revascularization. However, the safety and efficacy of the hybrid procedure in the setting of multivessel beating-heart TECAB and PCI have not been reported in the literature. To address this gap of knowledge, in this study, we reviewed the outcomes of patients who underwent advanced hybrid coronary revascularization (AHCR) defined as robotic beating-heart multivessel TECAB and PCI at our tertiary care center.

\section{MATERIALS AND METHODS \\ Study Population}

This is a retrospective single-center study approved by The Institutional Review Board of the University of Chicago Medical Center. We reviewed the outcomes of 308 consecutive patients undergoing TECAB from July 2013 to September 2017 at our institution. Among them, the outcomes of patients who underwent AHCR were summarized. Patient selection for AHCR was determined by hybrid revascularization team discussion between a robotic cardiac surgeon and interventional cardiologists. Inclusion criteria were patients who had left coronary diseases graftable by multivessel TECAB and the right coronary artery (RCA) or distal LCX diseases amenable to PCI or patients who had significant disease in the left main coronary artery. The absolute exclusion criteria were emergency cases, cardiogenic shock, and left pleural symphysis secondary to prior lung surgery. Relative exclusion criteria were poor pulmonary function (ie, patients who were expected not to tolerate single-lung ventilation) and redo cases.

\section{Hybrid Procedures}

TECAB was performed by a single experienced robotic cardiac surgeon with the da Vinci Si surgical robot (Intuitive Surgical Inc, Sunnyvale, Calif) with the aid of the C-Port Flex A distal coronary anastomotic connector (Dextera Inc, Redwood City, Calif). Our technique of robotic beatingheart TECAB has been described. ${ }^{4,6}$ Please see Video 1. All cases were planned to be performed on a beating-heart without cardiopulmonary bypass. Multivessel bypass is performed with BITA grafts use or sequential grafting of either one of the internal thoracic arteries. The LAD bypass is performed in all patients by using the left internal thoracic artery (LITA) or the right internal thoracic artery (RITA). In addition, the LCX, ramus branch, or diagonal branch is anastomosed as a second target. Our preference is to graft the LAD with the LITA and the LCX (or high diagonal) with the RITA. However, in cases where the RITA graft could not reach the second target, the RITA is grafted to the LAD and the LITA to the second target. The C-Port Flex A distal coronary anastomotic connector was applied in every end-to-side anastomosis.

Planned PCI is performed before, simultaneous, or after TECAB. Generally, a $6 \mathrm{~F}$ sheath is used for access. For percutaneous intervention for chronic occlusions, the sheath is upsized to an $8 \mathrm{~F}$, and dual injections (antegrade and retrograde) are performed for better lesion assessment. Angiographically severe (stenosis $>70 \%$ ) disease is intervened upon. For angiographically moderate disease (stenosis $50 \%-70 \%$ ), fractional flow reserve assessment is performed to determine the significance of the lesion. Second-generation drug-eluting stents are used unless there is a contraindication for prolonged dual antiplatelet therapy. When the planned PCI is performed after the TE$\mathrm{CAB}$, the bypass grafts are assessed for patency. Graft patency was assessed using the Fitzgibbon classification: grade A less than 50\% stenosis, grade B more than $50 \%$ stenosis, and grade $\mathrm{O}$ total occlusion. ${ }^{8}$

\section{Outcome Measures}

We summarized baseline patient characteristics, TECAB outcomes including 30-day mortality, postoperative morbidity, length of hospital stay and patency of the grafts according to the Fitzgibbon classification,

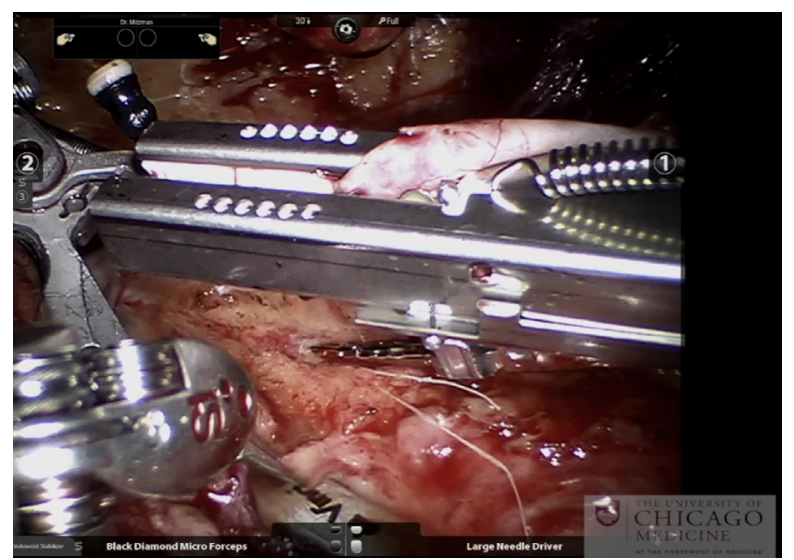

VIDEO 1. LITA-LAD anastomosis using the Flex A device (Dextera Inc, Redwood City, Calif) during TECAB. Video available at: https://www. jtcvs.org/article/S0022-5223(18)32937-4/fulltext. 
TABLE 1. Preoperative patient characteristics

\begin{tabular}{lc}
\hline \multicolumn{1}{c}{ Variables } & AHCR $(\mathbf{N}=\mathbf{5 7})$ \\
\hline Age, $\mathrm{y}$ & $65.6 \pm 8.8$ \\
\hline Female gender, $\mathrm{n}(\%)$ & $12(21.1)$ \\
\hline Body mass index $>35 \mathrm{~kg} / \mathrm{m}^{2}, \mathrm{n}(\%)$ & $6(10.5)$ \\
Hypertension, $\mathrm{n}(\%)$ & $49(86.0)$ \\
\hline Dyslipidemia, $\mathrm{n}(\%)$ & $46(80.7)$ \\
Diabetes mellitus, $\mathrm{n}(\%)$ & $19(33.3)$ \\
\hline Chronic renal failure, $\mathrm{n}(\%)$ & $9(15.8)$ \\
\hline Renal failure on dialysis, $\mathrm{n}(\%)$ & $3(5.3)$ \\
\hline COPD, $\mathrm{n}(\%)$ & $3(5.3)$ \\
Congestive heart failure, $\mathrm{n}(\%)$ & $12(21.1)$ \\
\hline Atrial fibrillation, $\mathrm{n}(\%)$ & $3(5.3)$ \\
Cerebrovascular accident, $\mathrm{n}(\%)$ & $6(10.5)$ \\
\hline Prior myocardial infarction, $\mathrm{n}(\%)$ & $18(31.6)$ \\
\hline STS risk score & $1.66 \pm 2.13$ \\
\hline 3-vessel disease, $\mathrm{n}(\%)$ & $46(80.7)$ \\
\hline Left main coronary artery disease, $\mathrm{n}(\%)$ & $11(20.8)$ \\
\hline Chronic total occlusion, $\mathrm{n}(\%)$ & $17(29.8)$ \\
\hline
\end{tabular}

Continuous variables are presented as mean \pm standard deviation. $A H C R$, Advanced hybrid coronary revascularization; $C O P D$, chronic obstructive pulmonary disease; STS, Society of Thoracic Surgeons.

PCI outcomes including rate of drug-eluting stent use, target lesions, number of arteries and lesions stented, and success rate. Midterm survival and freedom from major adverse cardiac events (MACE), including death, myocardial infarction, and repeat revascularization, were calculated. The details of mortality and MACE were reviewed.

\section{Statistical Analysis}

Continuous variables are expressed as mean \pm standard deviation and were compared by using the Student $t$ test or Mann-Whitney $U$ test, as appropriate. Categoric and sequential variables are expressed as the number and percentage of patients, and were compared by the chi-square test or Fisher exact test, as appropriate. Kaplan-Meier analysis was applied for midterm survival and freedom from MACE. The statistical analyses were conducted using IBM SPSS 25.00 (IBM, Inc, Chicago, Ill).

\section{RESULTS}

\section{Patient Population}

During the study period, 308 consecutive patients underwent TECAB at our institution. Hybrid coronary revascularization (TECAB and PCI) was performed in 112 patients, among whom AHCR (multivessel TECAB and PCI) was applied in 57. The number of patients who underwent AHCR has gradually been increasing from 10 in 2014, 14 in 2015, to 18 in 2016. Of note, there were 308 TECABS and 161 conventional isolated CABG procedures at our institution during this time frame. Table 1 summarizes the preoperative patient characteristics in AHCR. The cohort contained 45 men with a mean age of $65.6 \pm 8.8$ years, 3 octogenarians (age $>80$ years), and 6 morbidly obese patients (body mass index $>35 \mathrm{~kg} / \mathrm{m}^{2}$ ). The mean Society of Thoracic Surgery risk score was $1.66 \pm 2.13$ (range, 0.4-
10.5). Preoperative coronary angiography detected 3vessel coronary disease in 46 patients $(80.7 \%)$, left main coronary artery disease in 11 patients $(20.8 \%)$, and chronic total occlusion in 17 patients $(29.8 \%)$.

\section{Totally Endoscopic Coronary Artery Bypass Outcomes}

Intraoperative TECAB data are presented in Table 2. Multivessel TECAB was successfully performed in all patients without conversion to a more extensive incision. Mean operative time was $318.4 \pm 51.0$ minutes. BITA grafting was used in 50 patients $(87.7 \%)$. Sequential grafting of the LITA was applied in 10 patients $(17.5 \%)$, and sequential grafting of the RITA was applied in 2 patients $(3.5 \%)$. Triple-vessel bypass was applied in 5 patients $(8.8 \%)$. The mean number of bypass grafts per patient was $2.1 \pm 0.3$. The second target vessel additional to the LAD was the obtuse marginal branch in 36 patients, the ramus branch in 11 patients, and the diagonal branch in 15 patients. Four patients $(7.0 \%)$ received left atrial appendage ligation concomitant with TECAB. Cardiopulmonary bypass was required in 1 patient $(1.8 \%)$ through femoral vessels because of intolerance of single-lung ventilation.

Postoperative outcomes are summarized in Table 3. Surgical site infection, postoperative myocardial infarction, stroke, and reexploration for bleeding were not observed. The mean length of intensive care unit and hospital stay was $1.4 \pm 0.8$ days and $3.0 \pm 1.3$ days, respectively. Of 57 patients, 6 were discharged to a rehabilitation facility and $51(90 \%)$ were sent directly home. Nine patients received PCI during the same hospitalization (2 simultaneous and 7 after TECAB). The mean duration of time between TECAB and PCI was 2 days (0-6 days). The mean length of hospital stay in patients who had PCI in the same hospitalization was 3.9 days, and the mean length of hospital stay in patients who had PCI in a different hospitalization was 2.9 days. There was no in-hospital or 30-day mortality.

Fifty-four patients received coronary angiography after TECAB as part of the hybrid procedure or follow-up at 3 months (mean). Sixty-three LITA grafts and 47 RITA grafts were assessed. Two LITA grafts $(3.1 \%)$ were classified as Fitzgibbon grade B, and 3 grafts $(4.8 \%)$ were classified as grade O. For RITA grafts, $3(6.4 \%)$ were classified as grade B, and $2(4.3 \%)$ were classified as grade O. The graft patency rate was $95.2 \%(60 / 63)$ for LITA grafts and $95.7 \%$ (45/47) for RITA grafts. Among the 5 patients who had graft occlusions, only 2 were treated with additional PCI at the time of the planned hybrid PCI. The graft patency was $95.2 \%(40 / 42)$ in the LCX and $93.3 \%$ $(14 / 15)$ in the diagonal branch.

\section{Percutaneous Coronary Intervention Outcomes}

Procedure characteristics of PCI are summarized in Table 4. Radial artery approach was performed in 19 
TABLE 2. Intraoperative totally endoscopic coronary artery bypass data

\begin{tabular}{|c|c|}
\hline Variables & $\begin{array}{c}\text { AHCR } \\
(\mathbf{N}=\mathbf{5 7})\end{array}$ \\
\hline Operative time, $\min$ & $318.4 \pm 51.0$ \\
\hline BITA use, n (\%) & $50(87.7)$ \\
\hline Sequential anastomosis, n (\%) & $12(21.1)$ \\
\hline 2-vessel bypass, $\mathrm{n}(\%)$ & $52(91.2)$ \\
\hline 3-vessel bypass, n (\%) & $5(8.8)$ \\
\hline Mean No. of bypass grafts per patient, $n$ & $2.1 \pm 0.3$ \\
\hline First target vessel: LAD, n (\%) & $57(100)$ \\
\hline $\begin{array}{l}\text { Second target vessel: obtuse marginal branch, n (\%) } \\
\text { Ramus branch, n (\%) } \\
\text { Diagonal branch, n (\%) }\end{array}$ & $\begin{array}{l}36(63.2) \\
11(19.3) \\
15(26.3)\end{array}$ \\
\hline Concomitant procedure, $\mathrm{n}(\%)$ & $4(7.0)$ \\
\hline CPB use, n $(\%)$ & $1(1.8)$ \\
\hline Conversion to sternotomy, $\mathrm{n}(\%)$ & $0(0.0)$ \\
\hline Perioperative blood transfusion use, $\mathrm{n}(\%)$ & $8(14.1)$ \\
\hline
\end{tabular}

patients. Drug-eluting stents were used in $95.9 \%$ of total number of stents (94/98). Mean number of arteries stented and number of lesions stented per patient were $1.2 \pm 0.4$ and $1.3 \pm 0.6$, respectively. Overall, an average of 3.4 lesions ( 2.1 by TECAB, 1.3 by PCI) were revascularized with AHCR. PCI was planned before TECAB in 4 patients $(7.0 \%)$, simultaneously in 2 patients $(3.5 \%)$, and after TE$\mathrm{CAB}$ in 51 patients $(89.5 \%)$. Mean duration of time between TECAB and PCI was 49 days (PCI after TECAB) and 57 days (PCI before TECAB). Target lesions were RCA only in 38 patients $(66.7 \%)$, LCX only in 4 patients (7.0\%), and multiple lesions in 13 patients $(22.8 \%)$. In 2 patients, careful review of the post-TECAB angiogram or functional assessment revealed the absence of significant lesions thought to be present preoperatively. There were 17 chronic total occlusions; of these, 11 lesions were treated by PCI and 6 by TECAB. All of the chronic total occlusion PCIs were performed after TECAB. PCI attempt was unsuccessful in 8 lesions of overall (including the 3 chronic total occlusions). Postprocedural course was uneventful without any complications.

\section{Midterm Outcomes}

Mean clinical follow-up term was $21.5 \pm 13.4$ months. Survival was $96.2 \%$ and $92.8 \%$ at 12 and 36 months, respectively, after AHCR (Figure 1). There were 3 mortalities (mean age, 64.3 years; mean Society of Thoracic Surgeons score, 5.1). The causes of death were gastrointestinal bleeding, pulmonary embolism, and unknown cause.
TABLE 3. Postoperative outcomes

\begin{tabular}{|c|c|}
\hline Variables & $\operatorname{AHCR}(\mathbf{N}=\mathbf{5 7})$ \\
\hline Extubation in OR, n (\%) & $21(36.8)$ \\
\hline Prolonged ventilation $(>24 \mathrm{~h}), \mathrm{n}(\%)$ & $3(5.3)$ \\
\hline Surgical site infection, $\mathrm{n}(\%)$ & $0(0.0)$ \\
\hline Acute kidney injury, n (\%) & $1(1.8)$ \\
\hline Myocardial infarction, n (\%) & $0(0.0)$ \\
\hline New atrial fibrillation, $\mathrm{n}(\%)$ & $11(19.3)$ \\
\hline Stroke or TIA, n (\%) & $0(0.0)$ \\
\hline Reexploration for bleeding, $\mathrm{n}(\%)$ & $0(0.0)$ \\
\hline ICU length of stay, $d$ & $1.4 \pm 0.8$ \\
\hline Hospital length of stay, $d$ & $3.0 \pm 1.3$ \\
\hline 30-d mortality, n (\%) & $0(0.0)$ \\
\hline LITA graft patency, $\%(\mathrm{~N}=63)$ & 95.2 \\
\hline RITA graft patency, $\%(\mathrm{~N}=47)$ & 95.7 \\
\hline
\end{tabular}

Continuous variables are presented as mean \pm standard deviation. AHCR, Advanced hybrid coronary revascularization; $O R$, operation room; TIA, transient ischemic attack; ICU, intensive care unit; LITA, left internal thoracic artery; RITA, right internal thoracic artery.

Freedom from MACE was $90.0 \%$ and $80.2 \%$ at 12 and 36 months, respectively, after AHCR (Figure 2). There was a total of 9 MACE, including 3 deaths $(5.3 \%), 1$ myocardial infarction $(1.8 \%)$, and 5 repeat revascularizations $(8.8 \%)$. Details of repeat revascularization were as follows: One patient had an in-stent restenosis (RCA lesion). Three patients had graft occlusion and received additional PCI on the same target. One patient had graft occlusion and received $\mathrm{CABG}$ at an outside hospital. Compared with patients who did not experience MACE, patients who experienced MACE had higher rates of chronic obstructive pulmonary disease (Table E1).

\section{DISCUSSION}

In this study, we summarized the outcomes of AHCR at our institution, defined as robotic beating-heart multivessel TECAB and PCI. This new treatment concept for patients with multivessel coronary disease at our institution has shown excellent early postoperative outcomes with short hospital stay, acceptable graft patency, and good midterm outcomes (Central Figure).

Hybrid coronary revascularization has emerged as a new treatment option for multivessel coronary artery disease. The principle of the concept is to take advantage of the surgical benefit of the LITA-LAD bypass while limiting the invasiveness and providing complete revascularization with PCI to the non-LAD vessels, expecting a similar or superior patency to that of saphenous vein grafts in non-LAD target vessels. ${ }^{1}$ MIDCAB has mainly been used in the majority of reports of hybrid revascularization and has provided noninferior outcomes compared with CABG. ${ }^{2,3}$ Recent randomized trials comparing the outcomes of 
TABLE 4. Percutaneous coronary intervention data

\begin{tabular}{lc}
\hline \multicolumn{1}{c}{ Variables } & $\begin{array}{c}\text { AHCR } \\
(\mathbf{N}=\mathbf{5 7})\end{array}$ \\
\hline Radial/femoral approach, $\mathrm{n}(\mathrm{N}=52)$ & $19 / 33$ \\
Mean No. of arteries stented per patient, $\mathrm{n}(\mathrm{N}=47)$ & $1.2 \pm 0.4$ \\
\hline Mean No. of lesions stented per patient, $\mathrm{n}(\mathrm{N}=47)$ & $1.3 \pm 0.6$ \\
Drug-eluting stent, \% & 95.9 \\
\hline Target to only the RCA, $\mathrm{n}(\%)$ & $38(66.7)$ \\
Target to only the LCX, $\mathrm{n}(\%)$ & $4(7.0)$ \\
Target to multiple lesions, $\mathrm{n}(\%)$ & $13(22.8)$ \\
\hline Unattempted case, $\mathrm{n}(\%)$ & $2(3.5)$ \\
\hline Unsuccessful PCI lesion, $\mathrm{n}(\%)$ & $8(14.0)$ \\
\hline $\begin{array}{l}\text { Continuous variables are presented as mean } \pm \text { standard deviation. } A H C R, \text { Advanced } \\
\text { hybrid coronary revascularization; } R C A, \text { right coronary artery; } L C X, \text { left circumflex; }\end{array}$ \\
PCI, percutaneous coronary intervention.
\end{tabular}

hybrid revascularization (MIDCAB and PCI) versus CABG suggested that mortality and the rate of repeat revascularization were similar at 1-year follow-up. ${ }^{9}$ In recent years, to achieve less invasiveness and earlier functional recovery, robotic-assisted coronary surgery has emerged as an alternative to MIDCAB as the surgical arm of hybrid coronary revascularization. The contribution of robotic assistance can vary from robotic-assisted LITA harvesting and small left anterior thoracotomy for manual anastomosis $^{10-12}$ to totally endoscopic bypass (TECAB) where the whole procedure is done robotically. ${ }^{13-16} \mathrm{Few}$ studies have looked at outcomes of hybrid revascularization with TECAB. Bonatti and colleagues ${ }^{15}$ summarized the outcomes of 226 patients who underwent hybrid TECAB ( $36 \%$ of the patients received multivessel bypass) with a good 5-year survival of $92.9 \%$.

Since 2013, we have been performing AHCR (multivessel TECAB and PCI) at our institution because of our contention that arterial grafting of a second left coronary target may be superior to PCI. This approach admittedly is an uncommon one among centers performing hybrid revascularization because few programs offer multivessel TECAB on a routine basis. In our study, there was no 30day mortality and acceptably low morbidity after multivessel TECAB. Bonaros and colleagues ${ }^{17}$ reported 90 advanced hybrid revascularization cases (66 arrested and 24 beating-heart TECABs with PCI) including 76 multivessel TECABs with excellent midterm outcomes, which is comparable to our results. Traditionally, conventional CABG is compared with multivessel PCI in high-risk populations in large randomized trials. The most recent guidelines recommend stratification of multivessel coronary artery disease based on the low $(\leq 22)$, intermediate $(23$ $32)$, and high SYNTAX score $(>32) .{ }^{18}$ CABG is the preferred option in patients with high SYNTAX score because of the lower need for repeat revascularization;

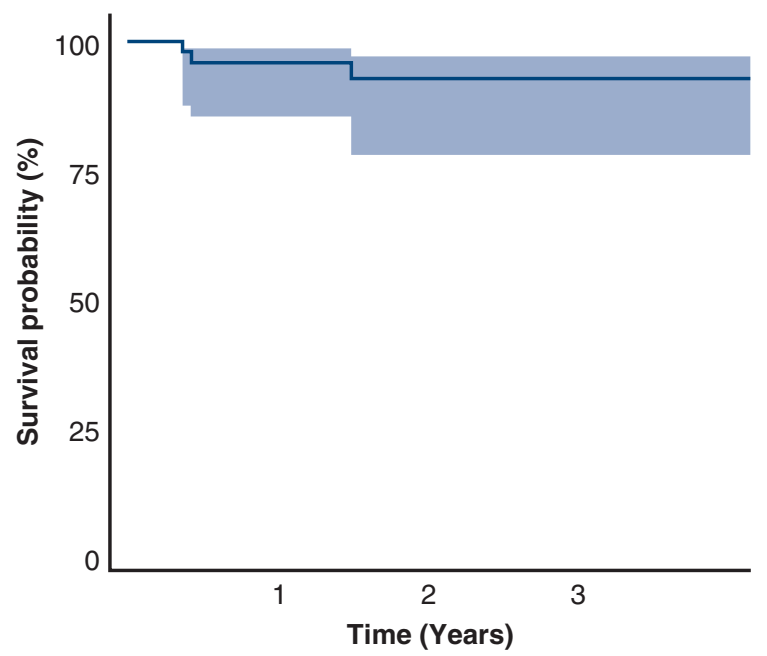

Number at Risk

$41 \quad 22 \quad 10$

FIGURE 1. Survival probability with $95 \%$ confidence interval.

however, the role of TECAB or less-invasive surgery has not been specified in the guidelines. Our midterm outcomes with AHCR were comparable to outcomes reported in the original SYNTAX trial, ${ }^{19}$ despite likely more complex anatomy because patients with lower SYNTAX score are generally treated with multivessel PCI at our institution.

The main advantage of TECAB in AHCR is considered to be early functional recovery. In our study, multivessel TECAB required relatively longer operative times (mean, 310 minutes) compared with single-vessel TECAB, similar to findings in a previous article by Bonatti and colleagues. ${ }^{20}$ However, our mean length of hospital stay was 3 days, which was comparable or shorter than that from a recent systematic review of robotic-assisted hybrid coronary surgery in which the length of hospital stay ranged from 4 to 8 days. ${ }^{21}$ In all but 1 of our patients, an offpump beating-heart procedure was performed, and this might play an important role in preventing a perioperative inflammatory reaction and enhancing early functional recovery. We believe that our use of anastomotic connectors for every anastomosis enables us to perform non-CPB beating-heart multivessel TECAB, shortens coronary ischemic time, and provides for excellent graft patency. ${ }^{4,22}$ Another important advantage of TECAB in AHCR is its capability of multivessel coronary bypass compared with other minimally invasive procedures (MIDCAB). Although Andrawes and colleagues ${ }^{23}$ reported their experience of multivessel MIDCAB (minimally invasive procedure) and concluded the number of bypassed vessels has increased at a later phase, revascularization was achieved with a single internal thoracic artery and vein grafts, not with bilateral internal thoracic arteries, and a minithoracotomy incision with rib spreading was required. A large 


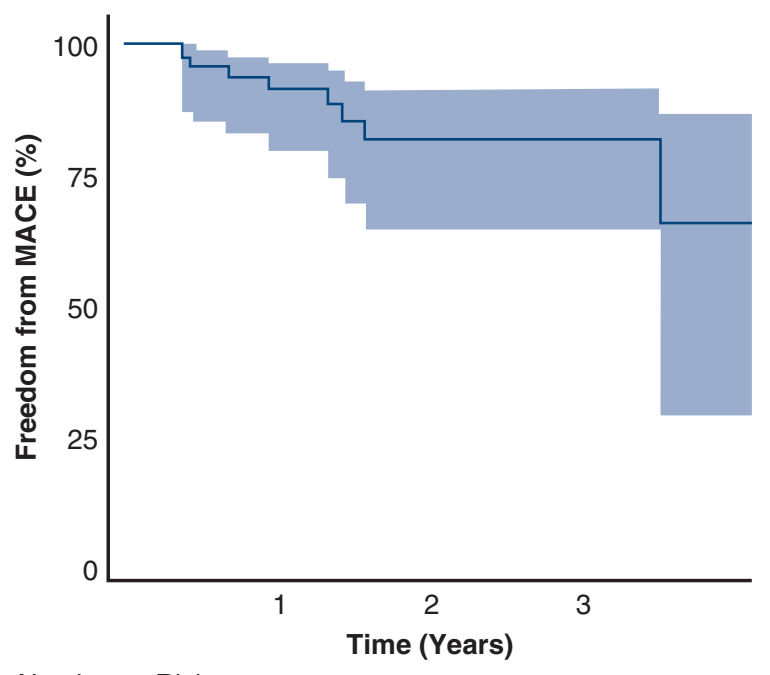

Number at Risk

$38 \quad 18 \quad 8$

FIGURE 2. Freedom from MACE with $95 \%$ confidence interval. $M A C E$, Major adverse cardiac events.

meta-analysis showed significantly improved survival in patients with BITA grafts compared with a single internal thoracic artery graft. ${ }^{24}$ However, based on the Society of Thoracic Surgeons National Database report, less than $4 \%$ of patients undergoing CABG receive BITA grafts, ${ }^{25}$ it may be due to a concern about increased risk of deep sternal infection, especially for high-risk patients. In our practice, BITA grafts are used in $52 \%$ of all patients receiving TECAB, and in the current study $88 \%$ of patients who underwent AHCR had BITA grafts. Concerns about the increased risk of sternal wound infection obviously do not exist in TECAB, even in diabetic and morbidly obese patients. $^{26}$

One area within this therapeutic space that deserves further investigation is timing of PCI relative to the surgery. From our data, 51 patients $(89 \%)$ received PCI after TECAB in the context of a planned hybrid approach. The rationale for performing the TECAB before PCI includes the following considerations:

1. Avoidance of dual antiplatelet therapy during the surgery.

2. Revascularization of a larger myocardial territory first via TECAB (vis-à-vis left coronary system vs [typically] the RCA).

3. The ability to confirm graft patency at the time of PCI, with the option for additional treatment of unexpected residual disease, if necessary ( 2 patients in our series who had graft occlusion received appropriate additional treatment by PCI).

4. Simplifying lesions previously not amenable for PCI into relatively simple lesions, which may expand treat- ment options. For example, a complex left main, LAD, LCX, bifurcation lesion can be treated with provisional single stent strategy from left main to LCX after confirming patency of the LITA-LAD graft at the time of PCI. In our study, among the 11 patients $(20.8 \%)$ who had left main coronary artery disease (which was previously not amenable to $\mathrm{PCI}$ ), 3 patients received provisional single-vessel stenting for the lesion protected by surgical bypass. Likewise, Lee and colleagues ${ }^{27}$ reported a case of left main trifurcation disease successfully converted to a simple ramus lesion for PCI postTECAB to LAD and LCX.

In this series, initial PCI attempt after TECAB failed in 8 lesions of 70 lesions (11\%), and all were difficult lesions ( 3 of 8 were complex chronic total occlusions of the RCA). Although the success rate of chronic total occlusion by PCI after TECAB was acceptable $(73 \%)$ in our data, overall there were still $14 \%$ of patients $(8 / 57)$ with residual disease. Because complete or near-complete revascularization, which is quantitatively and objectively assessed by SYNTAX score (residual SYNTAX score $<8$ ), has been reported to be associated with better long-term outcomes after $\mathrm{PCI}^{28}$ or $\mathrm{CABG},{ }^{29}$ the difficulty of PCI should be carefully evaluated during preprocedural planning for advanced hybrid therapy. Given this initial experience, we now consider on a case-by-case basis performance of PCI first in patients with non-LAD chronic total occlusions or other challenging lesion sets. If the PCI attempt fails, the treatment plan is adjusted accordingly to reconsider conventional multivessel CABG with a goal to achieve complete revascularization. In our program, the feasibility of complete revascularization is a critically important factor when deciding among available surgical and percutaneous options (ie, which grafts to use and which vessels to intervene on).

With the wide range of graftable TECAB targets (even in RCA lesions), ${ }^{6}$ acceptable graft patency regardless of quality of coronary target, and benefits of the hybrid concept, we believe that AHCR can expand the treatment indications for less-invasive complete revascularization. The cost of robotic equipment and the anastomotic connector was higher than for conventional CABG; however, we believe the overall costs were equivalent because of no CPB, less blood transfusions, and shorter intensive care unit and hospital stay. This should be evaluated in a formal cost-effectiveness analysis in the future. Furthermore, a randomized trial evaluating the clinical advantage of adding a second internal thoracic artery graft would be necessary to show the benefits of this approach. Establishing a dedicated hybrid revascularization team consisting of a robotic cardiac surgeon and team and interventional cardiologist were crucial to achieving these successful outcomes. 


\section{Study Limitations}

A limitation of the present study is its retrospective, single-institution, and single-surgeon nature. Although we did not exclude any patient because of higher-risk profiles, such as morbid obesity or octogenarians, patient selection was biased by referral pattern and patient's preference for minimally invasive surgery. The success of the advanced hybrid procedures was achieved by highly experienced surgical and interventional cardiology teams. Therefore, our results cannot be generalized widely in the absence of a dedicated robotic team with years of experience. The incompleteness of angiographic follow-up might affect the result of graft patency because only patients undergoing PCI after TECAB received angiographic assessment of their grafts.

\section{CONCLUSIONS}

AHCR, robotic beating-heart multivessel TECAB with PCI, is a safe approach with short hospital stay and good midterm outcomes when performed on a carefully selected cohort of patients by a surgeon and surgical team experienced with the techniques of TECAB. Our results suggest that this strategy might be considered as an option in the less-invasive treatment of multivessel coronary artery disease.

\section{Webcast}

You can watch a Webcast of this AATS meeting presentation by going to: https://aats.blob.core.windows.net/media/ 18Apr30/28ABC \%20Controversies \%20in \%20CABG/ S66\%20-\%20Part\%202/S66_9_webcast_051657911.mp4.

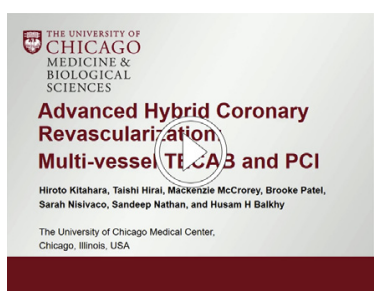

\section{Conflict of Interest Statement}

Dr Balkhy has disclosed that he is a proctor for Intuitive Surgical, manufacturer of the da Vinci robot. Dr Nathan has disclosed that he is a consultant and proctor for Medtronic, Inc. All other authors have nothing to disclose with regard to commercial support.

\section{References}

1. Yeung AC, Leon MB, Jain A, Tolleson TR, Spriggs DJ, McLaurin BT, et al. Clinical evaluation of the Resolute zotarolimus-eluting coronary stent system in the treatment of de novo lesions in native coronary arteries: the RESOLUTE US clinical trial. J Am Coll Cardiol. 2011;57:1778-83.

2. Holzhey DM, Cornely JP, Rastan AJ, Daviewala P, Mohr FW. Review of a 13year single-center experience with MIDCAB as the primary surgical treatment of CAD. Heart Surg Forum. 2012;15:E61-8.
3. Raja SG, Benedetto U, Alkizwini E, Gupta M, Harefield Cardiac Outcomes Research Group. Propensity score adjusted comparison of MIDCAB versus full sternotomy left anterior descending artery revascularization. Innovations (Phila). 2015;10:174-8.

4. Balkhy HH, Wann LS, Krienbring D, Arnsdorf SE. Integrating coronary anastomotic connectors and robotics toward a totally endoscopic beating heart approach: review of 120 cases. Ann Thorac Surg. 2011;92:821-7.

5. Bonaros N, Schachner T, Lehr E, Kofler M, Wiedemann D, Hong P, et al. Five hundred cases of robotic totally endoscopic CABG: predictors of success and safety. Ann Thorac Surg. 2013;95:803-12.

6. Balkhy HH, Nathan S, Arnsdorf SE, Krienbring DJ. Right internal mammary artery use in 140 robotic totally endoscopic coronary bypass cases: toward multiarterial grafting. Innovations (Phila). 2017;12:9-14.

7. Dorman MJ, Kurlansky PA, Traad EA, Galbut DL, Zucker M, Ebra G. Bilateral internal mammary artery grafting enhances survival in diabetic patients: a 30year follow-up of propensity score-matched cohorts. Circulation. 2012;18: 2935-42.

8. Fitzgibbon GM, Kafka HP, Leach AJ, Keon WJ, Hooper GD, Burton JR. Coronary bypass graft fate and patient outcome: angiographic follow-up of 5,065 grafts related to survival and reoperation in 1,388 patients during 25 years. J Am Coll Cardiol. 1996;28:616-26.

9. Gasior M, Zembala MO, Tajstra M, Filipiak K, Gierlotka M, Hrapkowicz T, et al. Hybrid revascularization for multivessel CAD. JACC Cardiovasc Interv. 2014; $1277-83$.

10. Adams C, Burns DJ, Chu MW, Jones PM, Shridar K, Teefy P, et al. Single-stage hybrid coronary revascularization with long-term follow-up. Eur J Cardiovasc Surg. 2014;45:442-3.

11. Bachinsky WB, Abdelsalam M, Boga G, Kiljanek L, Mumtaz M, McCarty C Comparative study of same sitting hybrid coronary artery revascularization versus off-pump coronary artery bypass in multivessel coronary artery disease. J Interv Cardiol. 2012;25:460-8.

12. Khaliel F, Giambruno V, Chu MWA, Sridhar K, Teefy P, Kiaii BB. Consequences of hybrid procedure addition to robotic-assisted direct coronary artery bypass. Innovations (Phila). 2017;12:192-6.

13. Gao C, Yang M, Wu Y, Wang G, Xiao C, Liu H, et al. Hybrid coronary revascularization by endoscopic robotic CABG on beating heart and stent placement. Ann Thorac Surg. 2009;87:737-41.

14. Katz MR, Van Praet F, de Canniere D, Murphy D, Siwek L, Seshadri-Kreaden U, et al Integrated coronary revascularization percutaneous coronary intervention plus robotic totally endoscopic coronary artery bypass. Circulation. 2006;114:1473-6.

15. Bonatti JO, Zimrin D, Lehr EJ, Vesely M, Kon ZN, Wehman B, et al. Hybrid coronary revascularization using robotic totally endoscopic surgery: perioperative outcomes and 5-year results. Ann Thorac Surg. 2012;94:1920-6.

16. Bonaros N, Schachner T, Wiedemann D, Weidinger F, Lehr E, Zimrin D, et al. Closed chest hybrid coronary revascularization for multivessel disease-current concepts and techniques from a two-center experience. Eur J Cardiothorac Surg. 2011;40:783-7.

17. Bonaros N, Schachner T, Kofler M, Lehr E, Lee J, Vesely M, et al. Advanced hybrid closed chest revascularization: an innovative strategy for the treatment of multivessel CAD. Eur J Cardiothorac Surg. 2014; 46:e94-102.

18. Patel MR, Calhoon JH, Dehmer GJ, Grantham JA, Maddox TM, Maron DJ, et al ACC/AATS/AHA/ASE/ASNC/SCAI/SCCT/STS 2017 appropriate use criteria for coronary revascularization in patients with stable ischemic heart disease: a report of the American College of Cardiology appropriate use criteria task force, American Association for Thoracic Surgery, American Heart Association, American Society of Echocardiography, American Society of Nuclear Cardiology, Society for Cardiovascular Angiography and Interventions, Society of Cardiovascular Computed Tomography, and Society of Thoracic Surgeons. J Am Coll Cardiol. 2017;69:2212-41.

19. Serruys PW, Morice MC, Kappetein AP, Colombo A, Holmes DR, Mack MJ, et al. Percutaneous coronary intervention versus CABG for severe coronary artery disease. N Engl J Med. 2009;360:961-72.

20. Bonatti J, Lee JD, Bonaros N, Schachner T, Lehr EJ. Robotic totally endoscopic multivessel coronary artery bypass grafting: procedure development, challenges, results. Innovations (Phila). 2012;7:3-8.

21. Wang N, Zhou JJ, Phan S, Yan TD, Phan K. Robot-assisted hybrid coronary revascularisation: systematic review. Heart Lung Circ. 2015;24:1171-9.

22. Balkhy HH, Wann LS, Arnsdorf S. Early patency evaluation of new distal anastomotic device in IMA grafts using computed tomography angiography. Innovations (Phila). 2010;5:109-13. 
23. Andrawes PA, Shariff MA, Nabagiez JP, Steward R, Azab B, Povar N, et al. Evolution of minimally invasive coronary artery bypass grafting: learning curve. Innovations. 2018;13:81-90.

24. Yi G, Shine B, Rehman SM, Altman DG, Taggard DP. Effect of bilateral internal mammary artery grafts on long-term survival: a meta-analysis approach. Circulation. 2014;130:539-45.

25. Tabata M, Grab JD, Khalpey Z, Edwards FH, O'Brien SM, Cohn LH, et al. Prevalence and variability of IMA graft use in contemporary multivessel coronary artery bypass surgery: analysis of the Society of Thoracic Surgeons National Cardiac Database. Circulation. 2009;120: 935-40.

26. Kitahara H, Patel B, McCrorey M, Nisivaco S, Balkhy HH. Morbid obesity does not increase morbidity or mortality in robotic cardiac surgery. Innovations (Phila). 2017;12:434-9.
27. Lee JD, Vesely MR, Zimrin D, Zimrin D, Bonatti J. Advanced hybrid coronary revascularization with robotic totally endoscopic triple bypass surgery and left main percutaneous intervention. J Thorac Cardiovasc Surg. 2012;144:986-7.

28. Faroog V, Serruys PW, Bourantas CV, Zhang Y, Muramatsu T, Feldman T, et al. Quantification of incomplete revascularization and its association with five-year mortality in the synergy between percutaneous coronary intervention with taxus and cardiac surgery (SYNTAX) trial validation of the residual SYNTAX score. Circulation. 2013;128:141-51.

29. Melina G, Angeloni E, Refice S, Benegiamo C, Lechiancole A, Matteucci M, et al. Residual SYNTAX score following CABG. Eur J Cardiothorac Surg. 2017;51:547-53.

Key Words: robotic, TECAB, hybrid revascularization, PCI

Readers who found these articles interesting may also like to read the following papers found in recent and future issues of our sister publications, Seminars in Thoracic and Cardiovascular Surgery and Operative Techniques in Thoracic and Cardiovascular Surgery!

\section{Adult: Coronary}

ORIGINAL SUBMISSION: Frozen Apex Repair of a Dilated Cardiomyopathy. Masashi Komeda. Semin Thoracic Surg 2018: Volume 30, Issue 4.

Editorial Commentary: The Frozen Apex: A Useful Addition to the Surgeons Armamentarium? James Kirklin. Semin Thoracic Surg 2018: Volume 30, Issue 4.

ORIGINAL SUBMISSION: Remote Ischemic Preconditioning in High Risk Cardiovascular Surgery Patients: a RandomizedControlled Trial. Nicole S. Coverdale. Semin Thoracic Surg 2018: 26-33.

Editorial Commentary: Remote Ischemic Preconditioning: a Complex Question with an Even More Complex Answer. Sarah A. Schubert. Semin Thoracic Surg 2018: 34-35. 
TABLE E1. Perioperative data in patients with or without major adverse cardiac events

\begin{tabular}{|c|c|c|c|}
\hline Variables & MACE $(+)$ & MACE (-) & $P$ value \\
\hline $\mathrm{N}$ & 9 & 47 & - \\
\hline Age, $y$ & $66.1 \pm 7.7$ & $65.5 \pm 9.1$ & .858 \\
\hline Female gender, $\mathrm{n}(\%)$ & $3(33.3)$ & $9(18.8)$ & .380 \\
\hline Hypertension, n (\%) & $7(77.8)$ & $42(87.5)$ & .599 \\
\hline Diabetes mellitus, n (\%) & $3(33.3)$ & $16(33.3)$ & 1.000 \\
\hline Chronic renal failure, n (\%) & $2(22.2)$ & $7(14.6)$ & .623 \\
\hline Renal failure on dialysis, $\mathrm{n}(\%)$ & $1(11.1)$ & $2(4.2)$ & .409 \\
\hline COPD, n $(\%)$ & $3(33.3)$ & $1(2.1)$ & .011 \\
\hline Congestive heart failure, $\mathrm{n}(\%)$ & $4(44.4)$ & $8(16.7)$ & .082 \\
\hline Chronic total occlusion, $\mathrm{n}(\%)$ & $4(44.4)$ & $14(29.2)$ & .442 \\
\hline STS risk score & $3.8 \pm 3.4$ & $1.3 \pm 1.5$ & .062 \\
\hline BITA use, n (\%) & $6(66.7)$ & $44(91.7)$ & .071 \\
\hline $\begin{array}{l}\text { Perioperative blood transfusion } \\
\text { use, } n(\%)\end{array}$ & $2(22.2)$ & $6(12.5)$ & .599 \\
\hline Unsuccessful PCI attempt, n (\%) & $3(33.3)$ & $5(10.4)$ & .103 \\
\hline
\end{tabular}

